\title{
Fetal and Postnatal Nicotine Exposure Modifies Maturation of Gonocytes to Spermatogonia in Mice
}

\author{
Rosa María Vigueras-Villaseñor $\mathbb{D}^{1},{ }^{1}$ Martín Alejandro Fuentes-Cano $\left(\mathbb{D},{ }^{2}\right.$ \\ Margarita Chávez Saldaña $\mathbb{D}^{1},{ }^{1}$ Liliana Rivera Espinosa $\mathbb{D}^{3}$, Rafael Reynoso-Robles $\mathbb{D}^{\mathbb{D}}{ }^{4}$ \\ Patricia Rojas $\mathbb{D}^{5}{ }^{5}$ Pilar Durán $\mathbb{D}^{2},{ }^{2}$ and Julio César Rojas-Castañeda $\mathbb{D}^{1}$ \\ ${ }^{1}$ Laboratorio de Biología de la Reproducción, Instituto Nacional de Pediatría, SS, Mexico City 04530, Mexico \\ ${ }^{2}$ Laboratorio de Biología Animal Experimental, Facultad de Ciencias, UNAM, Mexico City 04510, Mexico \\ ${ }^{3}$ Laboratorio de Farmacología, Instituto Nacional de Pediatría, SS, Mexico City 04530, Mexico \\ ${ }^{4}$ Laboratorio de Morfología Celular y Tisular, Instituto Nacional de Pediatría, SS, Mexico City 04530, Mexico \\ ${ }^{5}$ Laboratorio de Neurotoxicología, Instituto Nacional de Neurología y Neurocirugía, "Manuel Velasco Suárez", SS, \\ Mexico City 14269, Mexico
}

Correspondence should be addressed to Rosa María Vigueras-Villaseñor; rmvigueras@yahoo.com.mx and Julio César Rojas-Castañeda; rocajc1@yahoo.com.mx

Received 10 August 2020; Accepted 23 November 2020; Published 16 December 2020

Academic Editor: Ulises Urzua

Copyright (c) 2020 Rosa María Vigueras-Villaseñor et al. This is an open access article distributed under the Creative Commons Attribution License, which permits unrestricted use, distribution, and reproduction in any medium, provided the original work is properly cited.

\begin{abstract}
Studies in laboratory animals have shown that male offspring from dams, exposed to nicotine during pregnancy and postnatal periods, show alterations in fertility, although the origin of this is still uncertain. In this study, we examined in a mouse model if the process of gonocyte maturation to spermatogonia was affected in male offspring from dams with nicotine administration during pregnancy and postnatal periods. BALB/C mice, with and without nicotine administrations in pregnancy and postnatal periods, were studied. The animals were euthanized at $3,7,10,16$, and 35 days postpartum (dpp). Testicular tissue samples were processed for histological, ultrastructural, and immunohistochemical studies; and testicular lipoperoxidation was determined. It was observed that in the nicotine-exposed animals, there was increased apoptosis and a reduction in the number of gonocytes that matured to spermatogonia. This gonocyte-spermatogonia maturation reduction was associated with a greater immunoreactivity to nicotinic acetylcholine receptors in the germ cells. Lipoperoxidation was similar in both groups until $16 \mathrm{dpp}$, with significant reduction at $35 \mathrm{dpp}$. Our findings suggest that nicotine intake during pregnancy and postnatal periods can affect the process of maturation of gonocytes to spermatogonia and the pool of available spermatogonia for spermatogenesis.
\end{abstract}

\section{Introduction}

The World Health Organization report on smoking revealed that one-third of the world population are smokers. Cigarette has a variety of components including nicotine. Nicotine is a toxic alkaloid with a high addictive potential. It has the ability to cross through the placental barrier and to permeate into maternal milk of smoking mothers $[1,2]$. In addition, nicotine is associated with child mortality as well as premature births, abortion risk, and low birth weight that are associated with increased morbidity [3].
There are several studies showing the effect of nicotine exposure on male adult reproductive ability [4]. Also, the fertile capacity of sons from smoking mothers who indulge in smoking during pregnancy and lactation is affected [5-11].

The number of experimental studies using animal models and showing fertility alterations in offspring exposed to nicotine during pregnancy and lactation is scarce [12-16]. These studies were centered on offspring in adult stage. Their results depicted different alterations, such as low sperm count and decreased spermatogenesis and fecundability as well as reduced number of morphologically normal sperm cells 
[14]. However, the possible mechanisms of nicotine action on the maturation process of gonocytes to spermatogonia in the neonatal period, which is crucial for a successful fertility, are not known. The gonocytes arise during the embryonic development, a time when the primordial germ cells migrate to the gonadal crest. Gonocytes are located in the center of the seminiferous cords. In humans, their maturation to spermatogonia, in this place, begins at the tail end of the third period of gestation and continues until the first six months of life. In mice, this occurs in the first six days postpartum (dpp) $[17,18]$. During this process, the gonocytes usually migrate to the basement membrane and may or may not proliferate. This migration to the basement membrane is important for the survival of the gonocytes, since there is apoptotic death to those that remain in the center of the cord [19]. On the other hand, the number of spermatogonia is decisive for adequate sperm concentration. Nonetheless, the action of nicotine could be direct, because testicular tissue possesses nicotinic acetylcholine receptors (nAChR), and early germ cells of Sertoli and Leydig cells possess an $\alpha 7$ subunit of these receptors. It was suggested that $\mathrm{nAChR}$ might mediate cell divisions, metabolism, and motility in testicular tissue [2022]. Furthermore, nicotine can have an indirect action, such as the generation of oxidative stress through either an increase in the concentrations of reactive species, deficiency of endogenous antioxidant system, $[10,23,24]$ or altering the hormone concentrations $[13,16]$.

Therefore, the aim of this study was to determine, in a model of mice, whether the offspring from dams with exposition to nicotine during pregnancy and postnatal periods showed affectation in gonocyte survival, its proliferation, and maturation to spermatogonia, as well as to determine the participation of $\mathrm{nAChR}$ and lipoperoxidation in such process.

The results obtained indicated that nicotine intake during pregnancy and postnatal periods can affect the process of maturation of gonocytes to spermatogonia and the pool of available spermatogonia for spermatogenesis.

\section{Materials and Methods}

2.1. Animals. Albino mice $\mathrm{BALB} / \mathrm{c}$ bred and housed at the vivarium of Facultad de Ciencias, UNAM, were maintained under standard colony conditions. Administration of food (Rodent Lab Chow 5001, Purina Inc.) and water was ad libitum. The animals were kept in a temperature- and lightcontrolled room (12:12 h light-dark cycle, temperature between 22 and $24^{\circ} \mathrm{C}$, and humidity 40-50\%). In order to obtain the experimental offspring, males of $25 \mathrm{~g}$ and females of $20 \mathrm{~g}$ were kept together overnight to mate, and the following morning, the females were separated and checked by inserting a vaginal tampon; this day was recorded as day 0 of gestation. Later, the animals were divided into two groups: control and nicotine exposed.

At birth, litters were standardized to 8 pups (6 males/2 females). We used only the male offspring, and these were maintained at the vivarium until sacrifice, with weaning at $21 \mathrm{dpp}$. Thirty male pups from each group (control and nicotine exposed) were assigned to five age subgroups
( $n=6$ each) as follows: (1) $3 \mathrm{dpp}$ (the age when clear maturation of gonocytes to spermatogonia is observed); (2) $7 \mathrm{dpp}$ (the age when the maturation of gonocytes to spermatogonia culminates with few or no gonocytes present); (3) $10 \mathrm{dpp}$ (the age that later stages of spermatocytes appear beyond leptotene); (4) $16 \mathrm{dpp}$ (the age when pachytene spermatocytes are detected), and (5) $35 \mathrm{dpp}$ (the age of completion of spermatogenesis) [18].

All animals were treated in line with the ethical principles and regulations approved by the Animal Care and Use Committee (INV/B/RGC/107/18; Instituto Nacional de Pediatría, SS) and in accordance with Mexican NOM 062-200-1999, technical specifications for the reproduction, care, and use of laboratory animals (D.F. 22-VIII-01).

2.2. Nicotine Administration. Nicotine (Nic-Select ${ }^{\circledR}$ commercial trade used for electronic cigarette) was administered at $6 \mathrm{mg} / \mathrm{kg} /$ day to dams in drinking water ad libitum $[25,26]$ for 10 days before mating. The dose was maintained during mating, pregnancy, and lactation until weaning ( $21 \mathrm{dpp}$ ). Later, it was administered to pups in drinking water until $35 \mathrm{dpp}$. This method of administration was chosen to reduce manipulation stress [27]. The dose administered to the pups is equivalent to a heavy cigarette smoker who consumes from 1.5 to 3 packs/day $[25,26]$. Water intake and body weight were recorded every 3 days throughout the exposure period. In addition, these data were used to adjust the nicotine quantity throughout the treatment.

All the mice were euthanized using an overdose of sodium pentobarbital $(100 \mathrm{mg} / \mathrm{kg}$, IP; Pfizer, Toluca, Estado de Mexico, Mexico) between 12:00 and 13:00 h with the objective of preventing circadian fluctuations. The testes were extracted, weighed, and washed in saline solution (0.9\%). Each testis was half-sliced and placed on dry ice, immediately stored at $-70^{\circ} \mathrm{C}$, and used to determine lipoperoxidation. The other half was divided in parts-one for embedding in Epon 812 (Ted Pella, Inc., Redding, CA, USA) and the other for inclusion in paraffin.

2.3. Cotinine Concentration Determination. Cotinine is the major metabolite of nicotine with a longer half-life (approximately $20 \mathrm{~h}$ ) than nicotine $(20-60 \mathrm{~min})$ [28]. A drop of peripheral blood from each animal was collected on Whatman $903^{\circledR}$ filter paper cards (GE Healthcare Bio-Sciences Corp; Piscataway, NJ, USA). Each card was horizontally dried for $6 \mathrm{~h}$ at room temperature $\left(25 \pm 1^{\circ} \mathrm{C}\right)$. Once dried, the cards were properly labelled and stored in a drying material packed in plastic bags with low gas permeability $\left(-80^{\circ} \mathrm{C}\right)$ until analyzed. The entire circle was used for the quantification of cotinine. Ethyl acetate (Merck, Darmstadt, Germany) ( $1 \mathrm{~mL}), 10 \mu \mathrm{L}$ of ascorbic acid (Merck) (1\%), and $10 \mu \mathrm{L}$ of $1 \%$ ammonium hydroxide (Merck) were used for extraction. Chromatographic separation was carried out using Acquity UPLC equipment with an XSelect HSS Cyano, $2.1 \times 150$ $\mathrm{mm}, 5 \mu \mathrm{m}$ (Waters ${ }^{\circledR}$ ) adjusted to $40^{\circ} \mathrm{C}$. The mobile phase consisted of $0.1 \%$ formic acid (Merck) in $5 \mathrm{mM}$ ammonium formate (Sigma-Aldrich, St. Louis, MO, USA): acetonitrile (EMD Millipore $\mathrm{Co}^{\circledR}$, Mexico) $(50: 50 \mathrm{v} / v)$ at $0.3 \mathrm{~mL} / \mathrm{min}$. LC-MS/MS (Quattro Micro ${ }^{\circledR}$; Waters Co. ${ }^{\circledR}$, Milford MA, 
USA) was used for analysis. Detection was done by ESI ${ }^{+}$. Cotinine was measured in SRM mode, and ion transition was $177.26>80.14$. Data were processed with MassLynx ${ }^{\circledR}$ 4.1 software. With the conditions described, the test was linear over the concentration range of cotinine 0.5 to $10 \mathrm{ng} / \mathrm{mL}$.

2.4. Morphological Evaluation of the Gonocytes. Testicular tissue samples were fixed in modified Karnovsky solution without $\mathrm{Ca}^{2+}$ for $2 \mathrm{~h}$. Later, they were postfixed in $1 \% \mathrm{OsO}_{4}$ (Merck), dehydrated, and processed for embedding in Epon 812 (Ted Pella, Inc., Redding, CA, USA). Subsequently, the materials were sectioned at $1 \mu \mathrm{m}$ thick using an Ultracut UCT microtome (Leica, Vienna, Austria) and stained using $0.5 \%$ toluidine blue. The histological analysis of the seminiferous cords or tubules was performed using a BX 51 Olympus light microscope (Olympus Corp., Tokyo, Japan). Twenty to thirty transversal sections of the seminiferous cords or tubules per animal were evaluated. The area of seminiferous epithelium was determined by subtracting the internal area (tubular lumen) from the external area, using an image analyzing system (Image-Pro Plus 7.0, Media Cybernetics, Inc., MD, USA). The number of gonocytes (in contact or not) with the basement membrane and the number of spermatogonia were determined per seminiferous cord/tubule. The results were expressed per $1000 \mu \mathrm{m}^{2}$. Independent of the level of maturity of the gonocytes, we counted all those with evident nuclei in the section plane and classified them into types I, II, and III, as reported by Drumond et al. [18]. All histological examinations were performed by a single observer.

To confirm the presence of different types of gonocytes and their degeneration, the testicular tissues were sectioned at $60-70 \mathrm{~nm}$ thickness. Sections were stained with uranyl acetate and lead citrate and examined with a JEM-1011 (JEOL, Osaka, Japan) microscope.

2.5. Determination of Cell Proliferation and $\alpha 7-n A C h R$. The testicular samples were fixed in $4 \%$ paraformaldehyde for $2 \mathrm{~h}$, dehydrated, clarified, and embedded in paraffin. Sections of $4 \mu \mathrm{m}$ thickness were cut and mounted on slides with poly1-lysine (Sigma-Aldrich, St. Louis, MO, USA). The tissue sections were deparaffinized with xylene and hydrated through a graded ethanol series. Later, the sections were exposed to citrate buffer ( $\mathrm{pH} 7.6)$ for $5 \mathrm{~min}$ in a microwave oven set at $800 \mathrm{~W}$. Then, the sections were delineated by a Dako pen (Dako, Carpinteria, CA, USA). The tissue sections were treated with $3 \%$ hydrogen peroxide for $10 \mathrm{~min}$. Subsequently, they were placed in $0.1 \%$ Tween 20 (Sigma-Aldrich) phosphate-buffered saline (PBS, pH 7.4) solution for 10 min, blocked with $1 \%$ bovine serum albumin in PBS for $2 \mathrm{~h}$, and incubated overnight with primary antibody. To determine cell proliferation and nicotine receptors, the sections were incubated at room temperature with rabbitpolyclonal antibodies against phospho-histone H3, (Millipore Upstate, MA, USA) and $\alpha 7$-nAChR (ABCAM, Cambridge, MA), at a dilution of $1: 500$ and $1: 150$, respectively. Sections were then incubated with biotinylated antirabbit IgG (Santa Cruz Biotechnology, CA USA) at a $1: 100$ dilution for $1 \mathrm{~h}$ and then with streptavidin-peroxidase conju- gate (Rabbit ImmunoCruz staining system, Santa Cruz Biotechnology) for $30 \mathrm{~min}$ in accordance with the manufacturer's instructions. Tissue sections were incubated in a peroxidase substrate solution containing $1.6 \mathrm{~mL}$ of distilled $\mathrm{H}_{2} \mathrm{O}, 20 \mu \mathrm{L} 10 \mathrm{x}$ substrate buffer, and $40 \mu \mathrm{L}$ 50x diaminobenzidine chromogen (kit from Santa Cruz Biotechnology, CA, USA) and $1 \% \mathrm{H}_{2} \mathrm{O}_{2}$ (Merck) in methanol for $30 \mathrm{~min}$. Afterwards, they were counterstained with hematoxylin, dehydrated, and cleared with xylene. All dilutions and thorough washes between steps were performed using PBS unless otherwise specified. Negative control sections were processed in an identical manner but the primary antibodies were omitted. Tissue sections were mounted with Entellan mounting medium (Merck). The histological analysis of the seminiferous cords or tubules was performed by an observer with the help of a BX 51 Olympus light microscope. The number of proliferating germ cells was determined in twenty to thirty transversal sections of the seminiferous cords or tubules per animal and expressed per $1000 \mu \mathrm{m}^{2}$ tissue. All histological examinations were performed by a single observer.

2.6. Immunoreactivity (Optical Density) for $\alpha 7-n A C h R$ in Germ Cells. To determine variations in the protein expression at cellular level in the histological sections, we used optical density (OD). This is because OD has been used as a tool for indirect determination of the quantity of proteins in the histological sections. In addition, the results obtained with $\mathrm{OD}$ is similar to the results with biochemical techniques [29].

For OD analysis, digital images of tissue sections stained for $\alpha 7$-nAChR were captured at a magnification of $\times 100$. Thirty well-delimited cellular bodies with cellular nucleus evident were randomly chosen and outlined manually for each animal to measure OD.

The OD measurements (expressed as arbitrary OD units in $10 \mu \mathrm{m}^{2}$ ) were automatically determined using an image system (Image-Pro Plus 7.0, Media Cybernetics, Inc., MD, USA). For each of the cells, two background OD measurements were determined in nearby regions without immunoreactive profiles. The mean background $\mathrm{OD}$ value calculated was subtracted from the cellular OD value measured to obtain the final OD value [30].

2.7. Apoptotic Cell Determination. To determine apoptosis, terminal deoxynucleotidyl transferase dUTP nick end labeling (TUNEL) technique was used (in situ Cell Death Detection Kit, Roche Diagnostic Corporation, Indianapolis, IN, USA). The testicular portions were fixed in $4 \%$ paraformaldehyde for $18 \mathrm{~h}$. These tissue samples were dehydrated, clarified, and embedded in paraffin. Subsequently, a $4 \mu \mathrm{m}$ thickness was cut from each tissue sample and mounted on a slide covered with poly-l-lysine (Sigma-Aldrich). Next, they were deparaffinized and hydrated in a graded ethanol series. Sections were delineated with a Dako pen (Dako), treated with $0.1 \%$ Triton X-100 solution (Sigma-Aldrich) for $2 \mathrm{~min}$, and then incubated in TUNEL solution $(50 \mu \mathrm{L}$ terminal deoxynucleotidyl transferase and $450 \mu \mathrm{L}$ nucleotide mixture) for $1 \mathrm{~h}$ at $37^{\circ} \mathrm{C}$. For staining specificity, we processed some sections through all the incubation steps and treated them 
TABLE 1: Evaluated parameters (median and interquartile ranges) in control and nicotine-exposed animals.

\begin{tabular}{|c|c|c|c|c|c|c|c|c|}
\hline \multirow[t]{2}{*}{ Age (dpp) } & \multicolumn{2}{|c|}{ Body weight (g) } & \multicolumn{2}{|c|}{$\begin{array}{c}\text { Testicular weight/body } \\
\text { weight }\end{array}$} & \multicolumn{2}{|c|}{ Blood cotinine $(\mathrm{ng} / \mathrm{mL})$} & \multicolumn{2}{|c|}{$\begin{array}{l}\text { Area of seminiferous } \\
\text { cords/tubules }\left(\mu \mathrm{m}^{2}\right)\end{array}$} \\
\hline & Control & Nicotine & Control & Nicotine & Control & Nicotine & Control & Nicotine \\
\hline \multirow{2}{*}{3} & 2.360 & $1.990^{*}$ & 0.074 & 0.055 & 0.000 & $1.518^{*}$ & 2402.0 & 2573.9 \\
\hline & $2.140-2.370$ & $1.770-2.130$ & $0.042-0.443$ & $0.047-0.075$ & $0.000-0.000$ & $0.190-1.660$ & $1773.9-3476.9$ & 1773.9-3689.9 \\
\hline \multirow[b]{2}{*}{7} & 5.250 & 4.490 & 0.0761 & 0.069 & 0.000 & $3.778^{*}$ & 2997.9 & $2364.6^{*}$ \\
\hline & $4.890-5.360$ & $4.290-5.020$ & $0.061-0.093$ & $0.066-0.079$ & $0.000-0.000$ & $0.000-5.206$ & $2218.0-4236.9$ & $1466.1-3342.3$ \\
\hline \multirow{2}{*}{10} & 7.180 & 6.860 & 0.081 & 0.084 & 0.000 & $3.220^{*}$ & 5575 & $5191.8^{*}$ \\
\hline & $6.060-7.420$ & $5.960-7.750$ & $0.078-0.094$ & $0.078-0.090$ & $0.000-0.000$ & $2.539-4.005$ & $4645-6527$ & $3943.5-6667.0$ \\
\hline \multirow{2}{*}{16} & 7.300 & $6.850^{*}$ & 0.260 & 0.143 & 0.000 & $2.015^{*}$ & 9571 & $7096 *$ \\
\hline & $7.068-7.640$ & $6.590-7.050$ & $0.027-0.278$ & $0.131-0.151$ & $0.000-0.000$ & $1.015-2.253$ & 6994-13998 & 5182-9759 \\
\hline \multirow{2}{*}{35} & 20.770 & 22.510 & 0.285 & 0.270 & 0.000 & $1.158^{*}$ & 32542 & $27037^{*}$ \\
\hline & $17.530-24.020$ & $10.270-27.260$ & $0.212-0.333$ & $0.190-0.315$ & $0.000-0.000$ & $0.394-3.162$ & $25461-41177$ & $21388-37727$ \\
\hline
\end{tabular}

${ }^{*} p<0.05$ control vs. nicotine of the same age.

with DNase (Stratagene) at a concentration of $1 \mu \mathrm{g} / 1 \mathrm{~mL}$ for $10 \mathrm{~min}$ at $37^{\circ} \mathrm{C}$, before incubation in the TUNEL solution, to induce DNA strand breaks. These tissue sections were mounted with Entellan (Merck) for observation using an Olympus fluorescence microscope (Olympus BX51). The number of apoptotic cells per seminiferous cord/tubule was calculated, and the results were expressed as the number of apoptotic cells per $1000 \mu \mathrm{m}^{2}$. Twenty to thirty transverse sections of the seminiferous tubules per animal were evaluated. All dilutions and washes between steps were performed using PBS (0.1 M) unless otherwise specified. Negative control sections were processed in an identical manner but the enzyme solution (terminal deoxynucleotidyl transferase) was omitted. Slides from different ages were randomized and coded in such a way that all subsequent analyses were conducted in a blinded manner. All histological examinations were performed by a single observer.

2.8. Lipoperoxidation through Thiobarbituric Acid-Reactive Substances. Production of thiobarbituric acid-reactive substances (TBARS) was calculated according to the modified technique described for in vitro studies [31]. Due to the reduced size of the testes of $3,7,10$, and $16 \mathrm{dpp}$, we homogenized them in groups of nicotine and control per age. The testes of $35 \mathrm{dpp}$ were homogenized for each animal. For each homogenized tissue, $1 \mathrm{~mL}$ was taken and added to $2 \mathrm{~mL}$ of the thiobarbituric acid (TBA) reagent $(0.375 \mathrm{~g}$ of TBA, $15 \mathrm{~g}$ of trichloroacetic acid, and $2.5 \mathrm{~mL}$ of concentrated $\mathrm{HCl}$ in $100 \mathrm{~mL}$ of distilled water), and the final solution $(3 \mathrm{~mL}$ total volume) was heated in a hot bath for $30 \mathrm{~min}$. Samples were cooled and centrifuged at $3000 \times \mathrm{g}$ for $15 \mathrm{~min}$. The absorbance was measured in supernatants by spectrophotometry at $532 \mathrm{~nm}$. TBARS concentrations were calculated by the interpolation of a periodic oxidation of a malondialdehyde standard curve. The final result was expressed as nanomoles of TBARS per milligram of protein. Protein content in the testicular tissue samples was measured using the method of Lowry et al. [32]. The results of lipoperoxidation were normalized to the protein content in each sample.
2.9. Statistical Analysis. Data were expressed as median and interquartile ranges. Results were analyzed using MannWhitney $U$ test, comparing the experimental group versus the control group per age group. Values of $p<0.05$ were considered significant.

\section{Results}

3.1. Cotinine Concentration, Anatomy, Histology, and Lipoperoxidation. The presence of cotinine in blood was in all ages of the nicotine group, in contrast to what was observed in the control group ( $p<0.05$; Table 1$)$.

At 3 and $16 \mathrm{dpp}$, the nicotine-exposed group presented a significantly reduced body weight, compared with the control group $(p<0.05)$. However, at 7,10 , and $35 \mathrm{dpp}$, no significant differences in body weight were observed in animals of these ages when compared with the control group $(p>0.05$, Table 1). When testicular weight was analyzed in relation with body weight, there was no statistically significant difference in any of the age groups when compared with the controls $(p>0.05$, Table 1$)$.

Of the six animals with nicotine administration studied of $35 \mathrm{dpp}$, only one developed bilateral inguinal cryptorchidism. This animal was eliminated from histological and immunohistochemical studies, since cryptorchidism generates testicular histological alterations.

3.1.1. Animals of $3 d p p$. In the control group of $3 \mathrm{dpp}$; type I, II, and III gonocytes were observed in the central position; and some were in contact with the basement membrane (Figures 1(a), 2(a), and 2(b)). In this group, a major number of gonocytes in proliferation (Figure 3(a)) and the presence of cells in apoptosis (Figure 4(a)) were observed.

In the animals of $3 \mathrm{dpp}$ with nicotine administration, type I and II gonocytes were observed (Figures 1(b), 2(c), and 2(d)). The area of seminiferous cords in comparison with the control group did not show significant difference $(p>0.05$, Table 1). There was no significant difference in the number of gonocytes without contact with the basement membrane of both groups ( $p>0.05$, Table 2$)$. However, the 


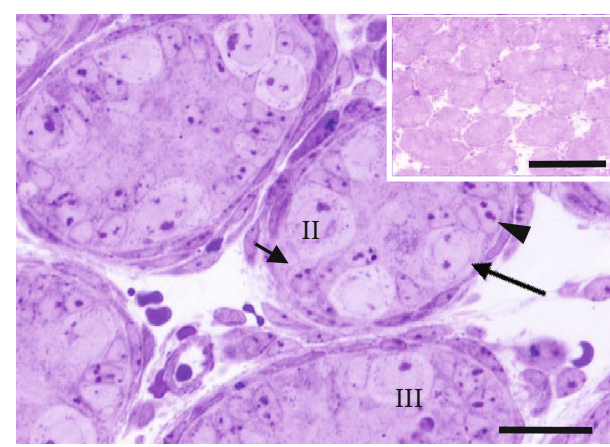

(a)

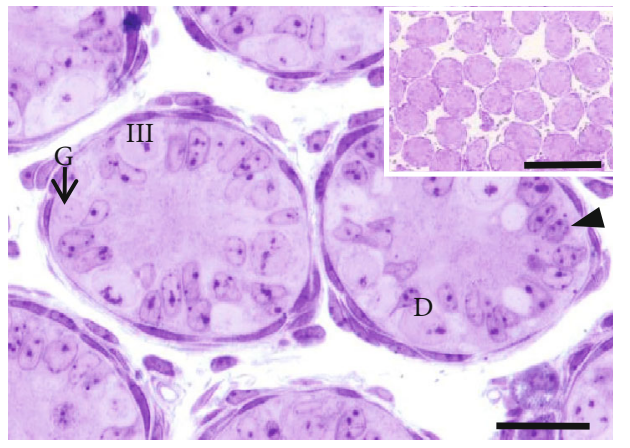

(c)

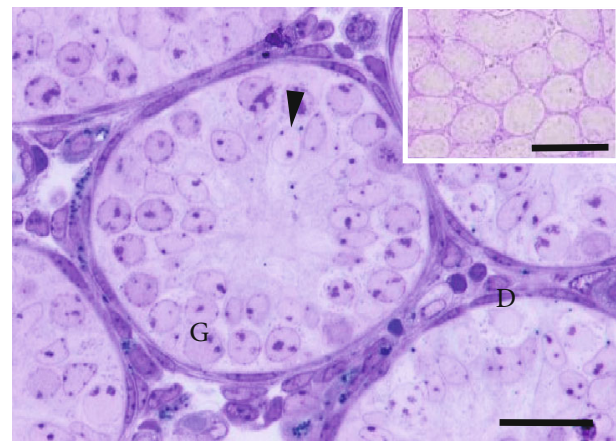

(e)

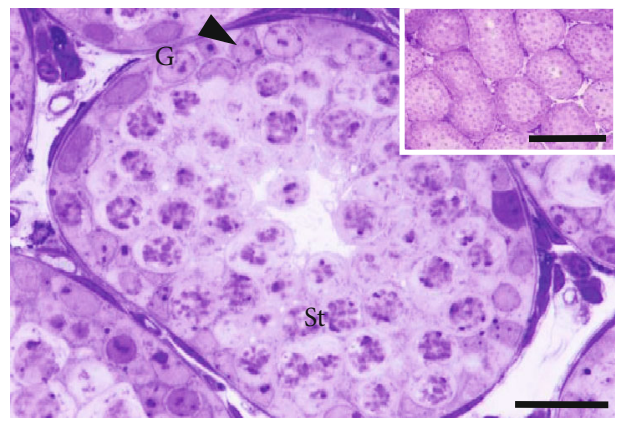

(g)

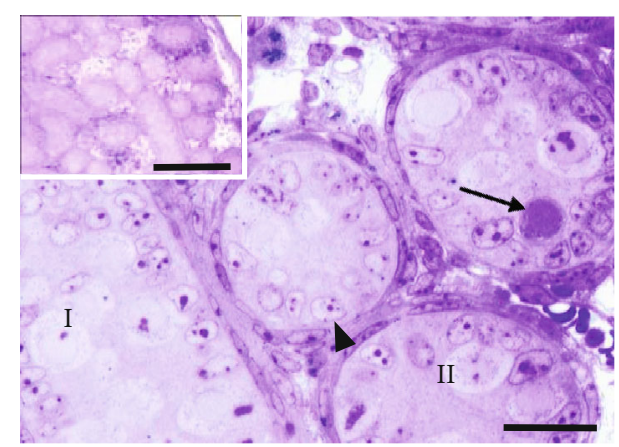

(b)

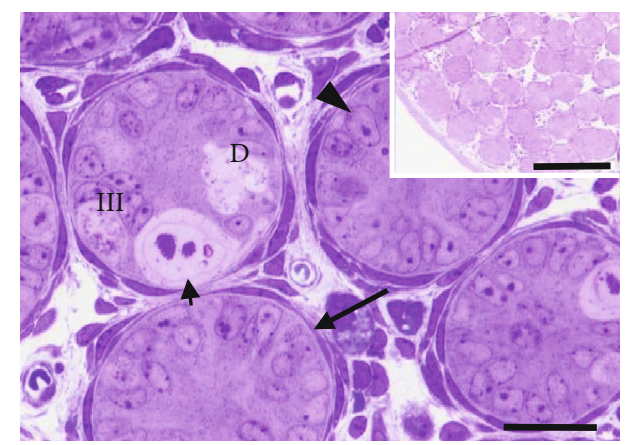

(d)

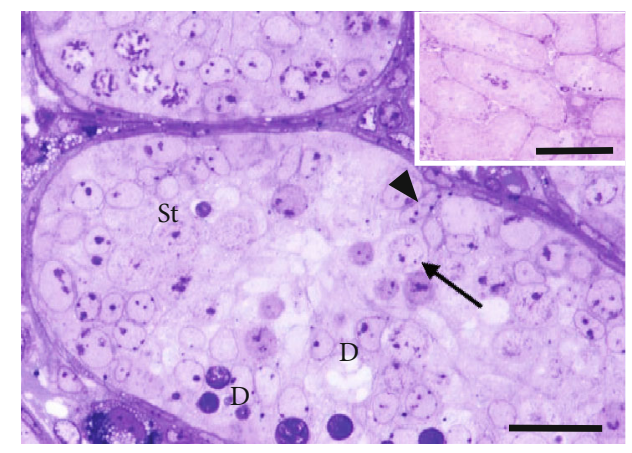

(f)

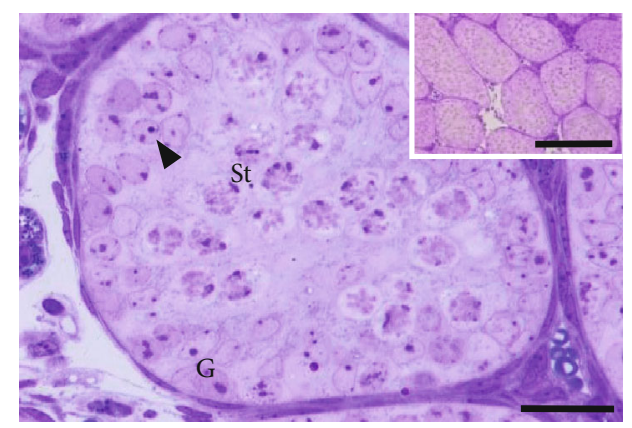

(h)

Figure 1: Continued. 


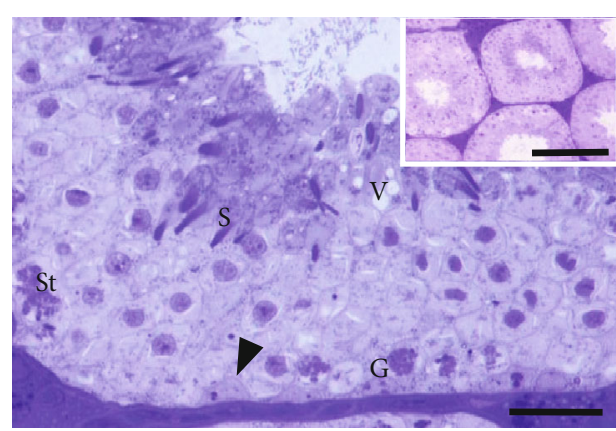

(i)

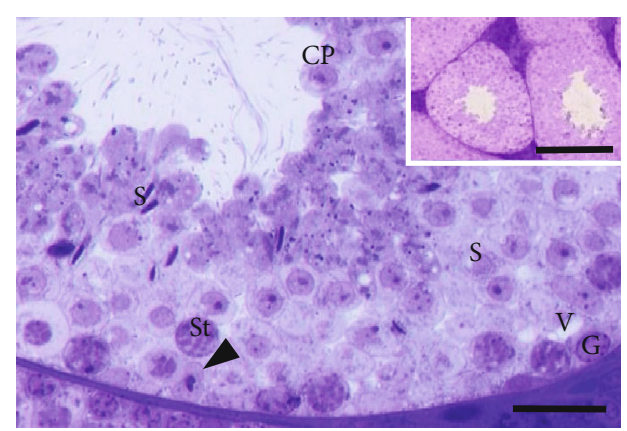

(j)

Figure 1: Seminiferous cords/tubules of the testes of control and animals with nicotine administration. (a) Control of 3 dpp, where we could observe subtype II gonocytes with cytoplasmic projections extending toward the basement membrane (short arrow) and subtype III gonocytes in contact with the basement membrane (large arrow) and Sertoli cell. (b) The nicotine group of 3 dpp, where we can appreciate subtype I and II gonocytes (some of which are not in contact with the basement membrane), degenerated gonocytes (arrow), and Sertoli cell. (c) Control of $7 \mathrm{dpp}$ subtype III gonocytes in contact with the basement membrane, type A spermatogonia, and Sertoli cell can be appreciated. (d) The nicotine group of $7 \mathrm{dpp}$, where we can observe degenerated subtype III gonocytes, giant gonocytes (short arrow), and Sertoli cell. Some cords did not have germ cells (large arrow). (e) Control of $10 \mathrm{dpp}$; gonocytes are not observed. There are spermatogonia in contact with the basement membrane and a great number of Sertoli cells. (f) Nicotine of $10 \mathrm{dpp}$. Germ cells without contact with the basement membrane (large arrow); some of these in degeneration (d) and Sertoli cell can be observed. (g) Control of $16 \mathrm{dpp}$, where we can observe spermatogonia, a great number of pachytene spermatocytes, Sertoli cells, and tubular lumen. (h) The nicotine group of $16 \mathrm{dpp}$ showing spermatogonia and a lower number of spermatocytes without tubular lumen. (i) Control of 35 dpp. A clear spermatogenesis with spermatogonia, spermatocytes, spermatids, Sertoli cell, and mild vacuolization (V) can be observed. (j) The nicotine group of $35 \mathrm{dpp}$, where we can observe the same characteristics as in (i) and mild cellular peeling. The insertions show the general panorama of the seminiferous cords/tubules. I = subtype I gonocytes; II = subtype II gonocytes; III = subtype III gonocytes; arrowhead = Sertoli cell nucleus; $\mathrm{G}=$ spermatogonia; $\mathrm{St}=$ spermatocyte; $\mathrm{S}=$ spermatids; $\mathrm{D}=$ cells in degeneration; $\mathrm{V}=$ vacuolization; $\mathrm{CP}=$ cellular peeling. Toluidine blue. Bar scale: $20 \mu \mathrm{m}$, insertion bar scale: $150 \mu \mathrm{m}$.

number of gonocytes in contact with the basement membrane and the number of cells in proliferation were significantly less in the group with nicotine administration $(p<0.05$, Table 2, Figures 1(b), 2(c), 2(d), and 3(b)) when compared with the control group. The number of cells in apoptosis was increased significantly in the group with nicotine exposure $(p<0.05$, Table 3, Figure $4(b))$.

3.1.2. Animals of $7 d p p$. In the control group of $7 \mathrm{dpp}$ (Figures 1(c), 2(e), and 2(f)), type III gonocytes in contact with the basement membrane and type A spermatogonia were seen. In addition, degeneration of some gonocytes was observed. In the nicotine group of this age, type II and III gonocytes and few type A spermatogonia were present. Moreover, degenerated giant gonocytes were observed (Figures 1(d), 2(g), and 2(h)). The area of the seminiferous cords, the number of germ cells in contact with the basement membrane, and the number of spermatogonia showed a significant decrease when compared with the control group $(p<0.05$, Tables 1 and 2). On the other hand, the number of cells in apoptosis $(p<0.05$, Table 3$)$ together with gonocytes without contact with the basement membrane was significantly higher in this group $(p<0.05$, Table 2$)$. Nevertheless, the proliferation showed no significant difference between both groups $(p>0.05$, Table 2$)$.

3.1.3. Animals of $10 \mathrm{dpp}$. In the control group of $10 \mathrm{dpp}$, no type of gonocytes was observed but the presence of spermatogonia A and B and a great number of Sertoli cells, together with cells in degeneration, were detected (Figure 1(e)). In this age, the nicotine group showed a histological structure similar to that of the control group (Figure 1(f)) although with a significantly higher number of cells in apoptosis $(p<0.05$, Table 3, Figures 4(c) and 4(d)). Degenerated germ cells and gonocytes without contact with the basement membrane were observed in the group exposed to nicotine (Figure 1(f)). The area of seminiferous cords and the number of cells in proliferation and of spermatogonia were significantly less when compared with the control group ( $p<0.05$, Tables 1 and 2 , Figures 3(c), 3(d), 4(c), and 4(d)).

3.1.4. Animals of $16 \mathrm{dpp}$. In the control and nicotine groups of $16 \mathrm{dpp}$, different types of spermatogonia and a higher number of pachytene spermatocytes were observed. In some seminiferous cords, the lumen began to appear (Figures $1(\mathrm{~g})$ and $1(\mathrm{~h}))$. The area of the seminiferous cords and the number of spermatogonia and of cells in proliferation were significantly less in the nicotine group when compared with control group $(p<0.05$, Tables 1 and 2$)$. The number of cells in apoptosis did not show significant difference when compared with the control group ( $p>0.05$, Table 3, Figures 4(e) and 4(f)).

Lipoperoxidation (TBARS) did not show significant differences when the nicotinic group was compared with the control group at ages $3,7,10$, and $16 \mathrm{dpp}(p>0.05$, Table 3$)$.

3.1.5. Animals of $35 \mathrm{dpp}$. At $35 \mathrm{dpp}$, different stages of development of the spermatogenesis, from spermatogonia to elongated spermatids, were observed in both the nicotine and control groups. The histological structure was similar in the two groups, since histological alterations, such as 


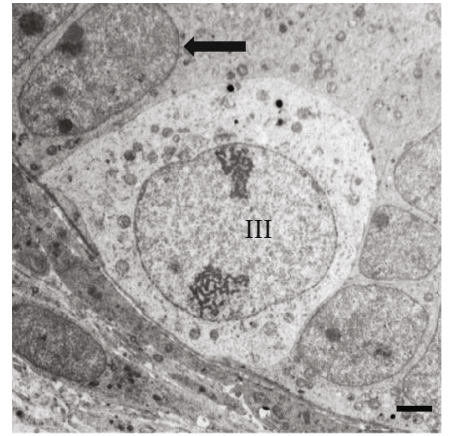

(a)

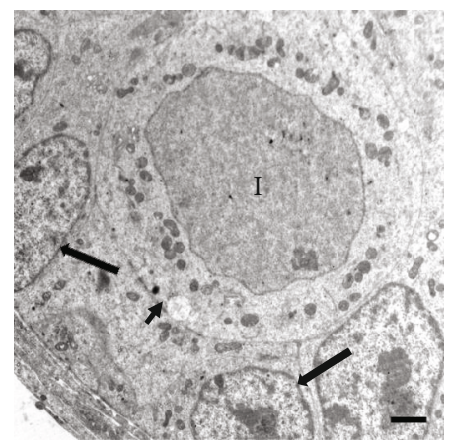

(d)

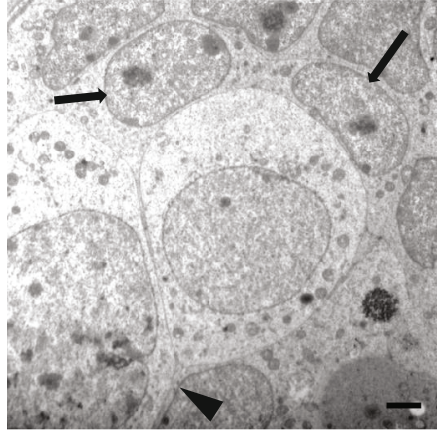

(b)

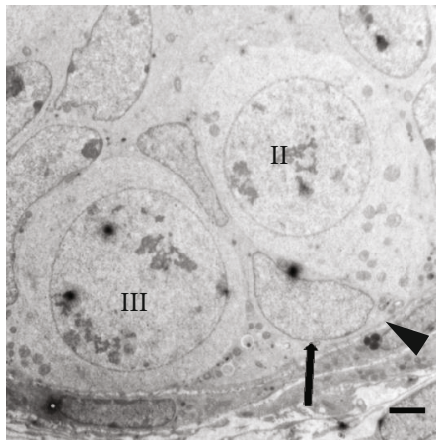

(e)

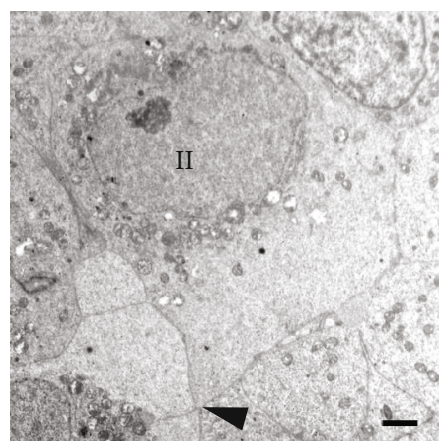

(c)

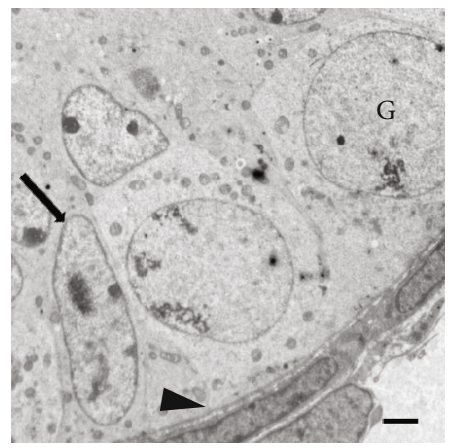

(f)

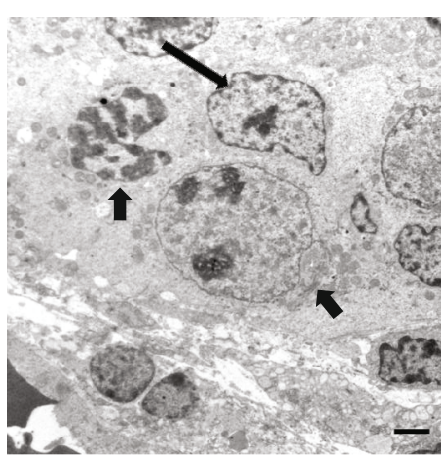

(g)

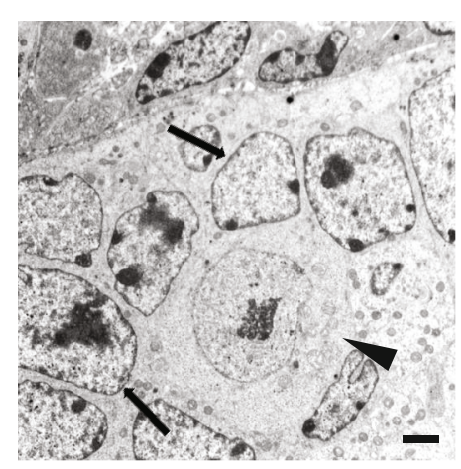

(h)

FIGURE 2: Seminiferous cords of the testes of control and animals with nicotine administration. (a, b) Control of 3 dpp, where we could observe subtype III gonocytes in contact with the basement membrane and in the process of migration to the basement membrane, with cytoplasmic projections extending toward the basal membrane (arrowhead) and Sertoli cell nuclei (arrow). (c, d) The nicotine group of $3 \mathrm{dpp}$, where we can appreciate subtype I and II gonocytes, some in the process of migration to the basement membrane with cytoplasmic projections extending toward the basement membrane (arrowhead) that could be observed to be in degeneration. The other gonocyte is not in contact with the basement membrane (short arrow). (e, f) Control of $7 \mathrm{dpp}$, where subtype III gonocytes in contact with the basement membrane and spermatogonia can be appreciated. Cytoplasmic projections extending toward the basement membrane can be observed (arrowhead). (g, h) The nicotine group of $7 \mathrm{dpp}$, where we can observe degenerated gonocytes (short arrow) and gonocytes without contact with the basement membrane (arrowhead). I = subtype I gonocytes; II = subtype II gonocytes; III = subtype III gonocytes; large arrow $=$ Sertoli cell nucleus, and $\mathrm{G}=$ spermatogonia. Electron microscopy. Bar scale: $2 \mu \mathrm{m}$.

vacuolization and cellular peeling, were present (Figures 1(i) and $1(j))$. The area of seminiferous tubules in the nicotine group was significantly less when compared with the control group ( $p<0.05$, Table 1) except at 7 days. The number of cells in apoptosis did not also show significant difference $(p>0.05$, Table 3); however, the number of spermatogonia and cells in proliferation was less in the nicotine group in comparison with the control $(p<0.05$, Table 2, Figures 3(e) and $3(f)$ ). Lipoperoxidation (TBARS) was significantly low in the nicotine group when compared with the control $(p<0.05$, Table 3).

3.2. Immunoreactivity (Optical Density) for $\alpha 7-n A C h R$. According to age, there was $\alpha 7-\mathrm{nAChR}$ immunoreactivity in gonocytes, spermatogonia, and spermatocytes. However, at 3,7 , and $10 \mathrm{dpp}$, OD was higher in the animals exposed to nicotine $(p<0.05)$. After this age, differences were not observed between both groups ( $p>0.05$, Figures $5(\mathrm{a})-5(\mathrm{~h})$, Table 3 ). 


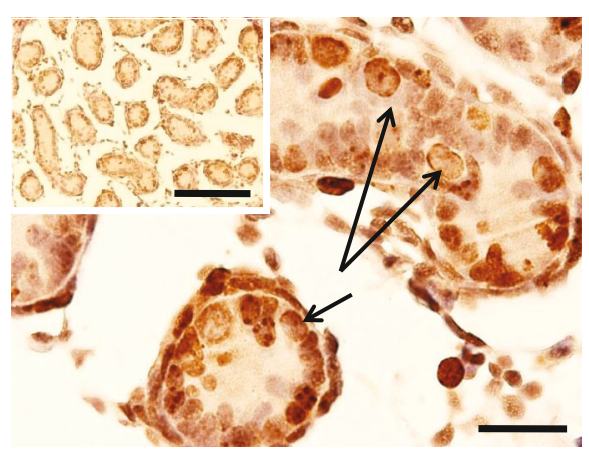

(a)

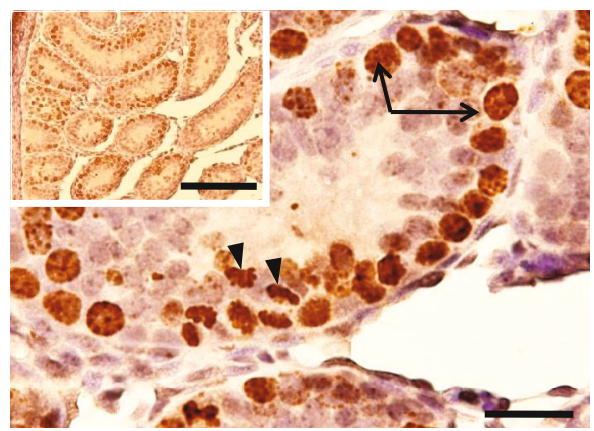

(c)

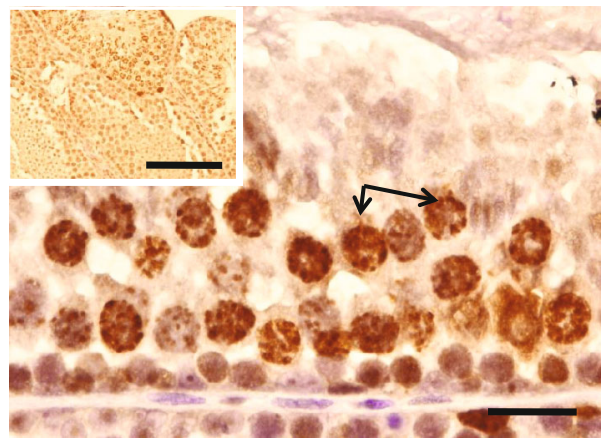

(e)

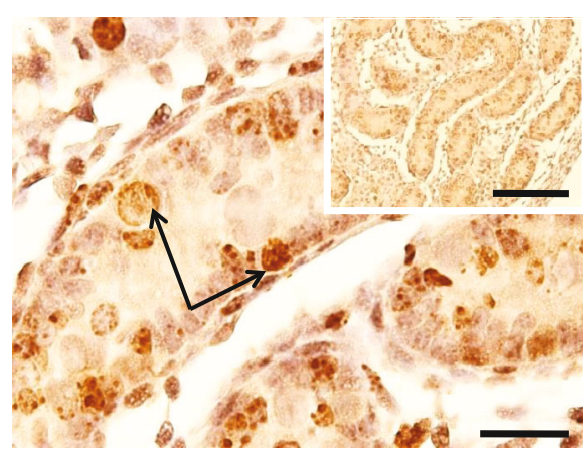

(b)

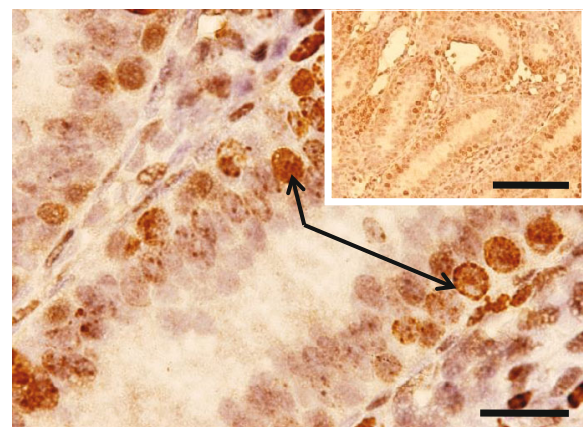

(d)

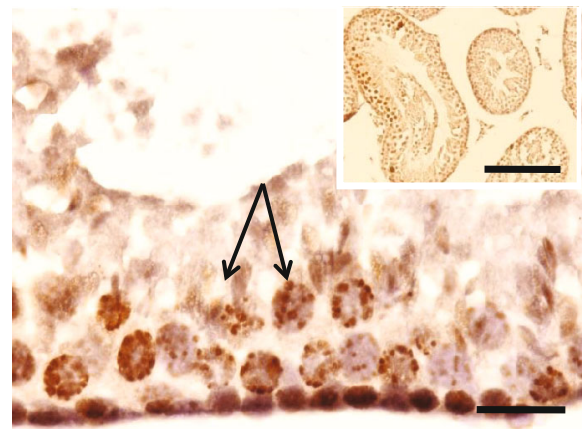

(f)

Figure 3: Seminiferous cords/tubules of mice: (a) control of $3 \mathrm{dpp}$, (b) nicotine group of $3 \mathrm{dpp}$, (c) control of $10 \mathrm{dpp}$, (d) nicotine of $10 \mathrm{dpp}$, (e) control of $35 \mathrm{dpp}$, and (f) the nicotine group of $35 \mathrm{dpp}$. A greater number of immunoreactive germ cells to phospho-histone $\mathrm{H} 3 \mathrm{protein}$ can be observed (arrow) in the seminiferous cords/tubules of control animals with respect to the nicotine group. Anaphase (arrowhead). Immunohistochemical study: bar scale: $20 \mu \mathrm{m}$, insertion bar scale: $150 \mu \mathrm{m}$.

\section{Discussion}

The consumption of cigarette during pregnancy and lactation in humans and animal models has been demonstrated to have adverse effects on the offspring [5-9, 11-14, 33].

Nicotine, one of the components of cigarette, quickly passes through the placental barrier and to the maternal milk in exposed rats $[1,2]$. In this study, the decrease in body weight of the newborn animals in the group exposed to this alkaloid might be related to an indirect effect of this substance, which reduces the availability of oxygen and blood flow to the fetus [34]. This leads to a decrease in birth weight as seen in heavy smokers $[35,36]$. A study in rat pups from dams with administration of nicotine at a dose of $0.5 \mathrm{mg} / \mathrm{kg}$, an inferior dose to the one used in this study, reported a significant reduction in body weight [27]. A reduction of $43 \%$ in the body weight of offspring proceeding from mice exposed to nicotine in gestation and in the first five days of postnatal life has been reported; nevertheless, these animals recovered their body weight at $35 \mathrm{dpp}$ [37]. In this study, the offspring also recovered their body weight at $35 \mathrm{dpp}$.

In our nicotine administration protocol, we identified one animal with inguinal bilateral cryptorchidism. With the technique of meta-analysis, a small increase in the risk of cryptorchidism following gestational exposition to cigarette smoke was reported [38]. Other authors found a close relationship between pregnancy and lactational nicotine exposition and development of cryptorchidism. To date, gestational smoking is considered a risk factor for the development of cryptorchidism [39, 40]. It is important to mention that 


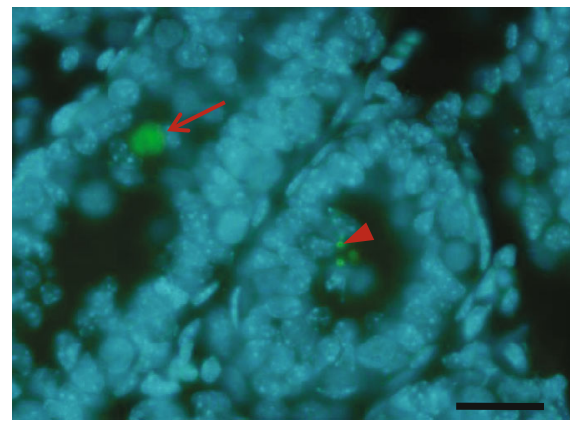

(a)

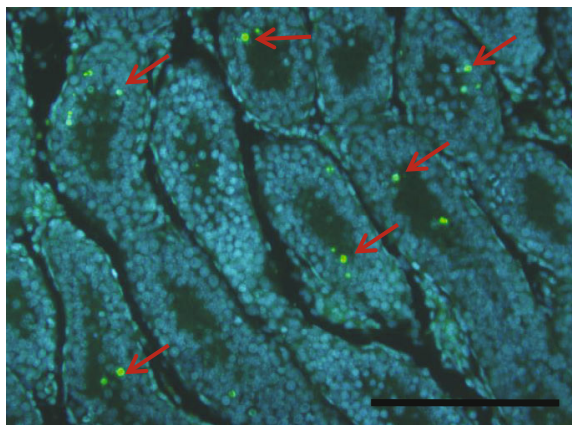

(c)

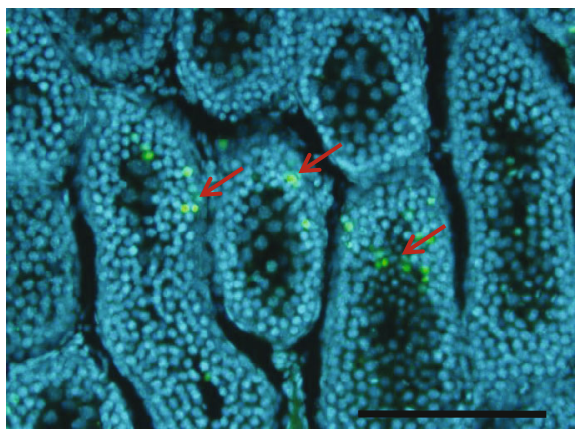

(e)

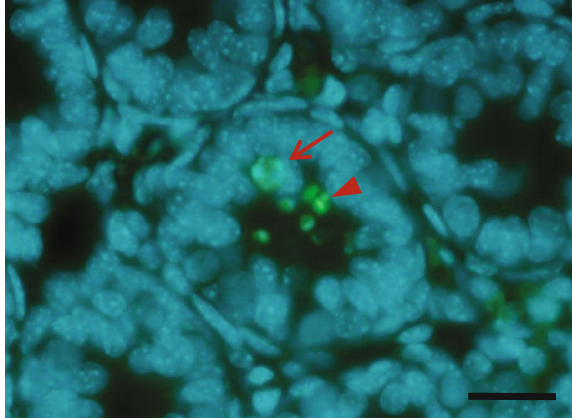

(b)

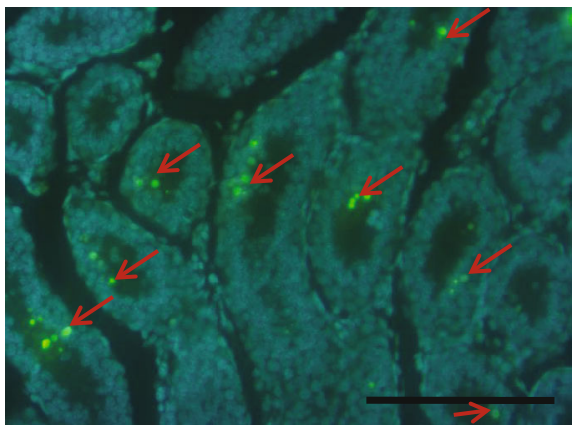

(d)

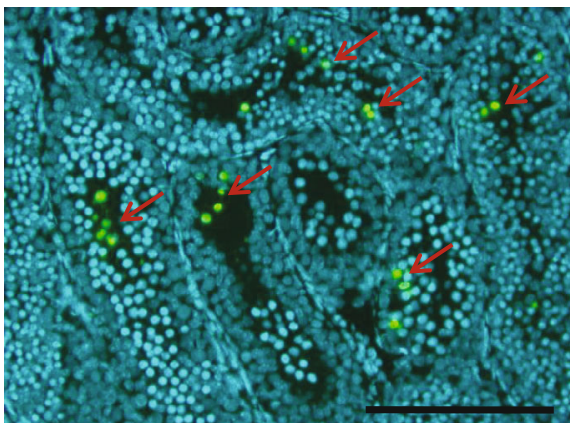

(f)

FIGURE 4: Seminiferous cords/tubules of mice: (a) Control of $3 \mathrm{dpp}$, (b) the nicotine group of $3 \mathrm{dpp}$, (c) control of $10 \mathrm{dpp}$, (d) the nicotine group of $10 \mathrm{dpp}$, (e) control of $16 \mathrm{dpp}$, and (f) the nicotine group of $16 \mathrm{dpp}$. Higher number of cells in apoptosis can be observed (arrow) in the seminiferous cords/tubules of mice with nicotine in comparison with the control group. Also, apoptotic bodies can be appreciated (arrowhead). TUNEL technique contrast with DAPI. (a, b) Bar scale: $20 \mu \mathrm{m}$; (c-f) bar scale: $150 \mu \mathrm{m}$.

testicular descent comprehends two stages, and the second of them depends on fetal testosterone. It has been reported that nicotine reduces the biosynthesis of testosterone; therefore, this could contribute to the development of cryptorchidism [41].

Alterations in reproduction in sons from mothers who smoked during pregnancy and lactation have been reported $[5-9,11,33]$. Most of the experimental works carried out with nicotine administration in these periods studied the organisms mainly at adult stage [12-16]. Lagunov et al. [12] focused their studies on the effect of in utero and lactational exposure to nicotine $(1 \mathrm{mg} / \mathrm{kg} / \mathrm{d}$ s.c.) on the reproductive tract of the offspring and reported histological alterations in the testes at 7 weeks of age. However, this was neither evident at 26 weeks of age nor was the sperm production affected, thus concluding that maternal nicotine exposure can induce transient structural changes in the testis and epi- didymis of male offspring. On the other hand, MirandaSpooner et al. [15] reported that the administration of nicotine $(2 \mathrm{mg} / \mathrm{kg} /$ day $)$ during the same periods did not generate testicular histological alterations at $90 \mathrm{dpp}$, but in longterm (143 and $196 \mathrm{dpp}$ ), there were cellular peeling and epithelial vacuolization. In all the ages studied, they observed abnormalities in the sperm head and tail. Paccola and Miraglia [16] found at 30,60, and $90 \mathrm{dpp}$ that nicotine exposure $(2 \mathrm{mg} / \mathrm{kg}$ per day) during intrauterine life and lactation caused intense sloughing of germ cell into the lumen, hence compromising the spermatogenesis in puberty and adulthood; however, these authors did not determine sperm parameters.

Sobinoff et al. [14] demonstrated that maternal cigarette smoke exposure during pregnancy/lactation induces severe neonatal/juvenile germ cell depletion. Aberrant testicular development characterized by abnormal Sertoli and germ cell 
TABLE 2: Evaluated parameters (median and interquartile ranges) in control and nicotine-exposed animals.

\begin{tabular}{|c|c|c|c|c|c|c|c|c|}
\hline \multirow[t]{2}{*}{ Age (dpp) } & \multicolumn{2}{|c|}{$\begin{array}{l}\text { Number of } G \text { in contact } \\
\text { with } \mathrm{BM} / 1000 \mu \mathrm{m}^{2}\end{array}$} & \multicolumn{2}{|c|}{$\begin{array}{l}\text { Number of G without } \\
\text { contact with } \mathrm{BM} / 1000 \mu \mathrm{m}^{2}\end{array}$} & \multicolumn{2}{|c|}{$\begin{array}{c}\text { Number of } \\
\text { spermatogonia/1000 } \mu \mathrm{m}^{2}\end{array}$} & \multicolumn{2}{|c|}{$\begin{array}{l}\text { Number of cells in } \\
\text { proliferation/1000 } \mu \mathrm{m}^{2}\end{array}$} \\
\hline & Control & Nicotine & Control & Nicotine & Control & Nicotine & Control & Nicotine \\
\hline \multirow{2}{*}{3} & 0.978 & $0.534^{*}$ & 0.416 & 0.654 & & & 10.380 & $6.072^{*}$ \\
\hline & $0.363-2.254$ & $0.273-1.352$ & $0.343-1.156$ & $0.307-1.515$ & & & $6.817-14.000$ & 2.539-9.539 \\
\hline \multirow{2}{*}{7} & 1.645 & $0.859^{*}$ & 0.010 & $0.409^{*}$ & 0.144 & $0.108^{*}$ & 1.1228 & 1.074 \\
\hline & 0.708-3.606 & $0.328-1.926$ & $0.010-0.343$ & $0.353-0.873$ & $0.123-0.364$ & $0.088-0.140$ & $0.324-1.868$ & $0.726-1.7462$ \\
\hline \multirow{2}{*}{10} & & & 0.010 & $0.199^{*}$ & 1.291 & $1.066^{*}$ & 5.122 & $3.162^{*}$ \\
\hline & & & $0.010-0.612$ & 0.124-0.406 & $1.003-1.665$ & $0.398-1.701$ & $1.396-8.267$ & $0.317-8.605$ \\
\hline \multirow{2}{*}{16} & & & & & 1.712 & $1.378^{*}$ & 2.114 & $1.784^{*}$ \\
\hline & & & & & $0.937-3.210$ & $1.005-1.761$ & $1.965-2.787$ & $1.093-2.290$ \\
\hline \multirow{2}{*}{35} & & & & & 0.912 & $0.517^{*}$ & 6.809 & $5.040^{*}$ \\
\hline & & & & & 0.524-1.489 & $0.216-0.892$ & $5.157-9.583$ & $3.102-7.630$ \\
\hline
\end{tabular}

${ }^{*} p<0.05$ control vs. nicotine of the same age. $\mathrm{G}=$ gonocyte; $\mathrm{BM}=$ basement membrane.

TABLE 3: Evaluated parameters (median and interquartile ranges) in control and nicotine-exposed animals.

\begin{tabular}{|c|c|c|c|c|c|c|}
\hline \multirow[t]{2}{*}{ Age (dpp) } & \multicolumn{2}{|c|}{$\begin{array}{l}\text { Number of cells in } \\
\text { apoptosis } / 1000 \mu \mathrm{m}^{2}\end{array}$} & \multicolumn{2}{|c|}{$\begin{array}{c}\text { TBARS (nmoles of TBARS per } \\
\text { mg of protein) }\end{array}$} & \multicolumn{2}{|c|}{$\begin{array}{c}\text { OD of } \alpha 7-\mathrm{nAChR} \\
\text { (arbitrary units } / 10 \mu \mathrm{m}^{2} \text { ) }\end{array}$} \\
\hline & Control & Nicotine & Control & Nicotine & Control & Nicotine \\
\hline 3 & $\begin{array}{c}0.351 \\
0.174-1.847\end{array}$ & $\begin{array}{c}0.825^{*} \\
0.583-1.847\end{array}$ & $\begin{array}{c}0.625 \\
0.433-0.841\end{array}$ & $\begin{array}{c}0.607 \\
0.310-0.834\end{array}$ & $\begin{array}{c}0.163 \\
0.035-1.464\end{array}$ & $\begin{array}{c}0.326^{*} \\
0.135-7.016\end{array}$ \\
\hline 7 & $\begin{array}{c}0.439 \\
0.124-2.150 \\
\end{array}$ & $\begin{array}{c}1.126^{*} \\
0.199-2.265 \\
\end{array}$ & $\begin{array}{c}0.625 \\
0.433-0.841 \\
\end{array}$ & $\begin{array}{c}0.607 \\
0.310-0.834 \\
\end{array}$ & $\begin{array}{c}0.208 \\
0.063-0.250 \\
\end{array}$ & $\begin{array}{c}0.290^{*} \\
0.118-0.575 \\
\end{array}$ \\
\hline 10 & $\begin{array}{c}0.692 \\
0.128-2.158 \\
\end{array}$ & $\begin{array}{c}1.197^{*} \\
0.185-4.183\end{array}$ & $\begin{array}{c}0.625 \\
0.433-0.841 \\
\end{array}$ & $\begin{array}{c}0.607 \\
0.310-0.834 \\
\end{array}$ & $\begin{array}{c}0.142 \\
0.034-0.244\end{array}$ & $\begin{array}{c}0.276^{*} \\
0.111-0.535 \\
\end{array}$ \\
\hline 16 & $\begin{array}{c}0.329 \\
0.042-5.723\end{array}$ & $\begin{array}{c}0.332 \\
0.053-2.947\end{array}$ & $\begin{array}{c}0.625 \\
0.433-0.841\end{array}$ & $\begin{array}{c}0.607 \\
0.310-0.834\end{array}$ & $\begin{array}{c}0.164 \\
0.038-0.280\end{array}$ & $\begin{array}{c}0.111 \\
0.003-0.263\end{array}$ \\
\hline 35 & $\begin{array}{c}0.199 \\
0.048-0.925\end{array}$ & $\begin{array}{c}0.136 \\
0.030-0.687\end{array}$ & $\begin{array}{c}0.355 \\
0.209-0.403\end{array}$ & $\begin{array}{c}0.097^{*} \\
0.065-0.174\end{array}$ & $\begin{array}{c}0.098 \\
0.089-0.269\end{array}$ & $\begin{array}{c}0.1458 \\
0.102-0.165\end{array}$ \\
\hline
\end{tabular}

${ }^{*} p<0.05$ control vs. nicotine of the same age.

organization, a depleted spermatogonial stem cell population, atrophic seminiferous tubules, and increased germ cell DNA damage persisted in adult offspring 11 weeks after exposure. These authors also found a reduction in the concentration and sperm motility, as well as an increase in its morphological alterations, thus reducing its fertilization capacity. In spite of the differences in our experimental model, their results, in the short term, coincide with what were reported in this work. Although Sobinoff et al. [14] did not focus on studying the gonocytes, they mentioned degeneration in this type of cell. In the present study, nicotine delayed the maturation of gonocytes to spermatogonia, as demonstrated by the presence of a higher number of gonocytes until $10 \mathrm{dpp}$.

The mechanism of damage by nicotine that produces lack of maturation of the gonocytes and their degeneration could be explained through different routes: (1) by its indirect action on the hypothalamic-pituitary-testicular axis that modified hormonal production and (2) by direct action on the testicular cells.
In this work, we were not able to determine if nicotine affected the concentrations of testosterone, $\mathrm{FSH}$, or $\mathrm{LH}$. The mechanism of damage by nicotine may involve a direct action on Sertoli cells which have been reported to be altered in laboratory animals with nicotine exposure during pregnancy and lactation $[14,16]$. Also, low concentrations of inhibin B in sons of mothers who smoked more than 10 cigarettes per day during pregnancy have been reported [5]. This hormone is produced by Sertoli cells in the testis, and it is positively associated with the function of this type of cell [42]. In vitro studies with Sertoli cells from prepubertal animals exposed to nicotine have demonstrated alterations in their functionality (reduced mRNA expression and protein levels of Anti-Mullerian Hormone (AMH) and inhibin B and impaired FSH-r), in addition to downregulation of $\mathrm{Bcl} 2$, which is considered a survival factor [43]. Sertoli cell is indispensable in the regulation of gonocyte proliferation for the participation of platelet-derived growth factor(PDGF-) BB, 17 $\beta$-estradiol (E2), leukemia inhibitory factor (LIF), and retinoic acid (RA) [44], as well as for the 


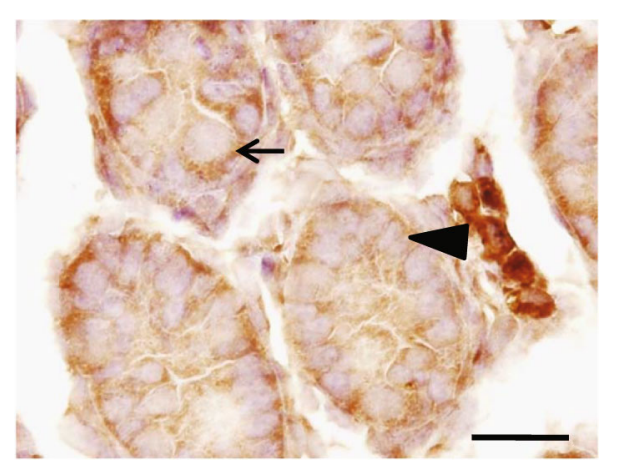

(a)

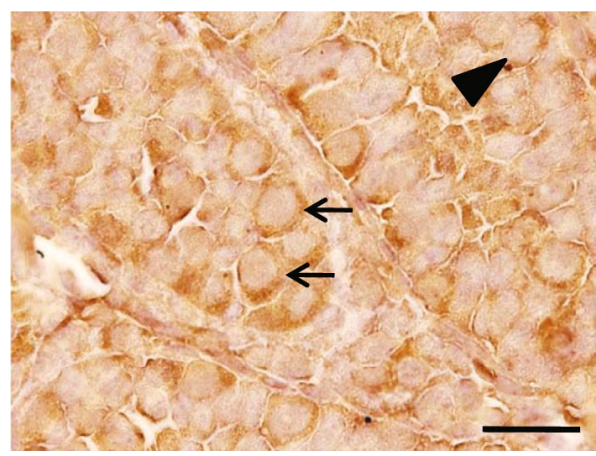

(c)

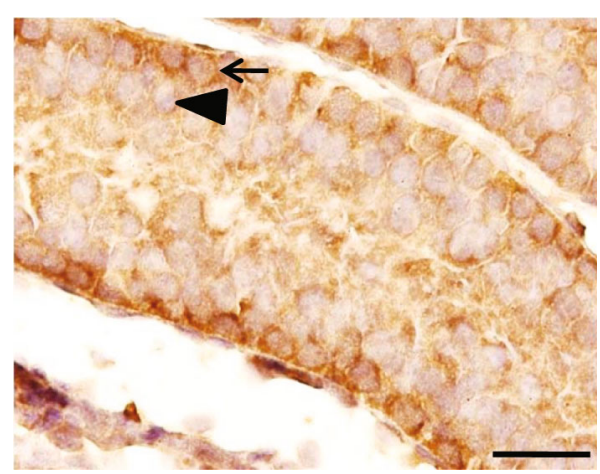

(e)

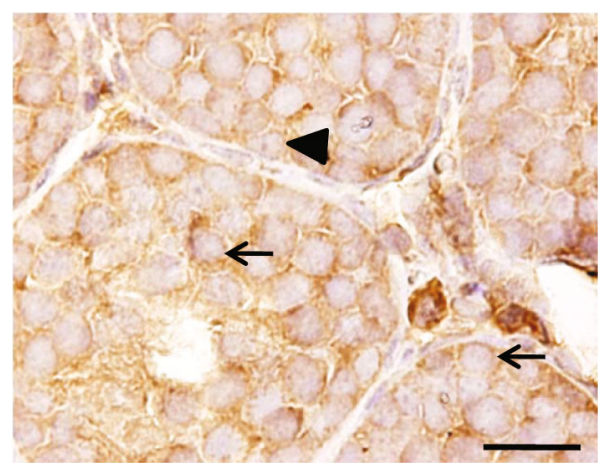

(g)

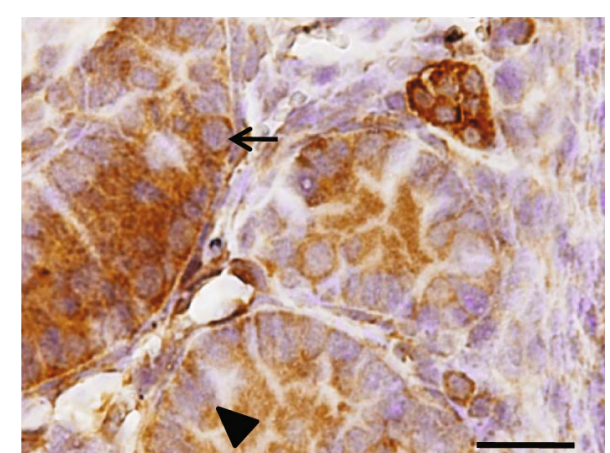

(b)

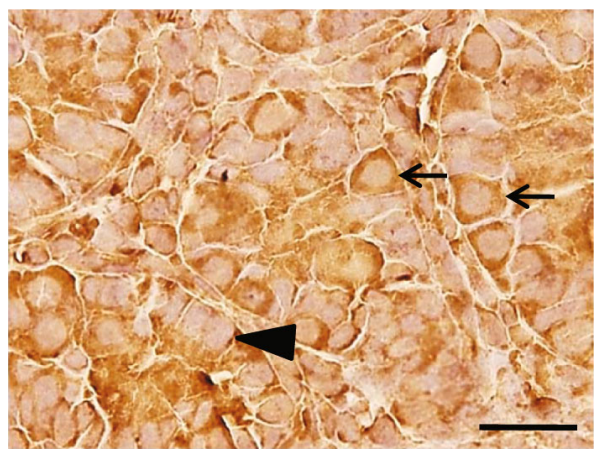

(d)

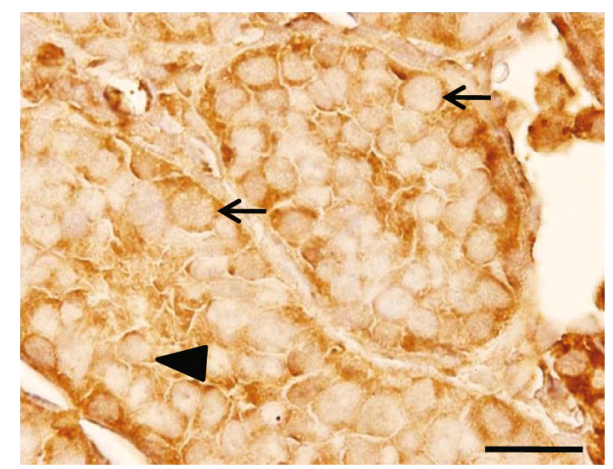

(f)

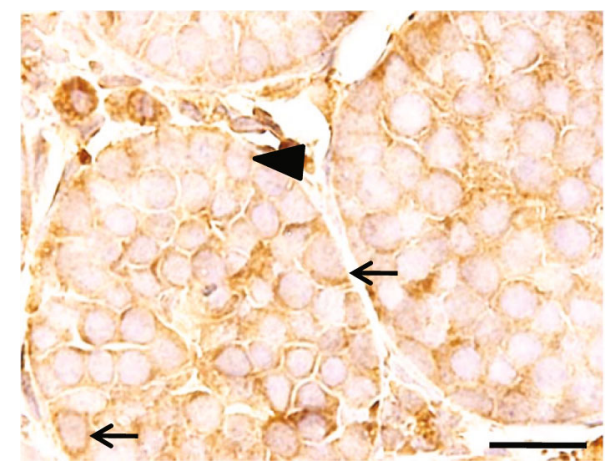

(h)

Figure 5: Seminiferous cords/tubules of mice: (a) control of $3 \mathrm{dpp}$, (b) the nicotine group of $3 \mathrm{dpp}$, (c) control of $7 \mathrm{dpp}$, (d) the nicotine group of $7 \mathrm{dpp}$, (e) control of $10 \mathrm{dpp}$, (f) the nicotine group of $10 \mathrm{dpp}$, (g) control of $16 \mathrm{dpp}$, and (h) the nicotine group of $16 \mathrm{dpp}$. Immunoreactivity of $\alpha 7$-nAChR in germ cells (arrow), as well as in Sertoli cells (arrowhead). Higher OD in germ cells of nicotine groups of 3, 7, and 10 dpp can be observed. In the animals of $16 \mathrm{dpp}$, the OD between both groups is not different. Immunohistochemical study: bar scale: $20 \mu \mathrm{m}$. 
maturation of gonocytes to spermatogonia by providing the factors such as RA, PDGF and its receptor, and AMH [19, $45,46]$. In case the gonocytes do not mature, the Sertoli cell provides proapoptotic proteins, such as transforming growth factor- $\beta$ (TGF) and FasL, thus activating pathways such as p53, p21 (WAF1/CIP1), and Bax that are known to participate in the testicle from early stages of development and can be activated by exposure to cytotoxic agents [47-49]. In addition, it has been demonstrated that nicotine acts by reducing mRNA and protein levels of $\mathrm{Bcl} 2$, as well as upregulating p53 and caspase- 3 mRNA, including protein levels, that adversely affects the germinal epithelium in adult rats [50].

Moreover, nicotine can have direct action on gonocytes. In our study, the presence of higher OD from $\alpha 7-\mathrm{nAChR}$ in the animals exposed to nicotine at 3,7 , and $10 \mathrm{dpp}$ may suggest that the mechanism of action of nicotine is direct on germ cells. Activated $\mathrm{nAChR}$ has been shown to increase ion influx, mainly $\mathrm{Ca}^{2+}$ [51]. It has been demonstrated that the increase in intracellular calcium of Sertoli cells (TM4) in vitro induced mitochondrial membrane depolarization. This produces the release of proapoptotic factors by activating the permeability transition pore and loss of mitochondrial membrane integrity [52-54].

It is likely that during the period of higher OD of $\alpha 7$ $\mathrm{nAChR}$ in the first three ages studied in this work $(3,7$, and $10 \mathrm{dpp}$ ), the apoptosis of a part of the gonocyte population took place. This hampered their migration to the basement membrane, which impeded their differentiation and led to a decreased germ cell population in proliferation. This event may have brought about the smaller area in the seminiferous tubules at $35 \mathrm{dpp}$. This may be reflected in a low volume of ejaculates and sperm count in humans $[4,5]$, as well as in laboratory animals [14].

On the other hand, it should be considered that exposition to tobacco causes damage to DNA, which accelerates senescence in different organs [55]. In addition to cell cycle arrest, senescent cells secrete an abnormal variety of molecules, including inflammatory cytokines, growth factors, reactive oxygen species (ROS), and extracellular matrix components that modify the cellular microenvironment, which, in turn, causes tissue dysfunction [56]. The testicular tissue develops senescence in elderly animals [57]; however, nicotine has not demonstrated to induce this process in the testicle.

Finally, the mechanism of reproductive damage by nicotine administration during pregnancy and postnatal periods can be through a route different from the theory of oxidative stress associated with nicotine as was postulated [10, 23, 24]. The absence of increases in lipoperoxidation in the nicotine animal groups of $3,7,10$, and $16 \mathrm{dpp}$, as well as the reduction in lipoperoxidation at $35 \mathrm{dpp}$ in the nicotine group, could be owed to an excellent testicular antioxidant system at these ages. Also, it could be due to an increase in the activity of enzymes, such as catalase (CAT) and superoxide dismutase (SOD) induced by alkaloid. There are reports that show an increase in the activity of brain SOD, testicular CAT, and testicular glutathione peroxidase (GPx), induced by the administration of different doses of nicotine in different stages of development [58-60]. An increase in the activity of these enzymes may lead to a decrease in the availability of reactive oxygen species.

This work does not include sperm count, serum testosterone, FSH, LH, and inhibin B measurement and antioxidant enzyme activities. These tests may give information on the mechanisms of damage generated by nicotine. Hence, we propose that further studies are necessary to know the mechanisms of damage generated by nicotine on maturation of gonocytes.

\section{Conclusions}

The present study shows that a direct action of the nicotine during pregnancy and postnatal period can alter the process of maturation from gonocytes to spermatogonia and affect the pool of available spermatogonia for spermatogenesis.

\section{Data Availability}

All data used to support the findings of this study are included within the supplementary information file.

\section{Ethical Approval}

All applicable international, national, and/or institutional guidelines for the care and use of animals were followed. All procedures performed in the studies involving animals were in accordance with the ethical standards of the institution or practice, at which the studies were conducted. The protocol was approved by the Animal Care and Use Committee of our institution (INV/B/RGC/107/18; Instituto Nacional de Pediatría, SS) and in accordance with Mexican NOM 062-ZOO-1999, technical specifications for the reproduction, care, and use of laboratory animals (D.F. 22-VIII-01).

\section{Conflicts of Interest}

The authors declare that there is no conflict of interest regarding the publication of this paper.

\section{Acknowledgments}

The authors are grateful to Pedro Medina Granados, Mercedes Edna García Cruz, and Edgar Daniel Cervantes Arias for their invaluable support in processing the samples. We thank Cyril Niddi Nwoye Nnamezie (MD), an expert translator whose native language is English, for his help in preparing the manuscript. This study was supported by the Mexican Federal Funding for Instituto Nacional de Pediatría (E022); by PD-LBAE-FC UNAM 2015-2018; PCBM-2016 at Facultad de Ciencias-UNAM, particularly the Laboratory of Experimental Animal Biology; and fellowship 364988 from CONACYT (296411, Martín Alejandro Fuentes Cano). 


\section{Supplementary Materials}

The data used to support the findings of this study are included within the supplementary information. (Supplementary Materials)

\section{References}

[1] D. S. Lambers and K. E. Clark, "The maternal and fetal physiologic effects of nicotine," Seminars in Perinatology, vol. 20, no. 2, pp. 115-126, 1996.

[2] K. S. Lips, D. Bruggmann, U. Pfeil, R. Vollerthun, S. A. Grando, and W. Kummer, "Nicotinic acetylcholine receptors in rat and human placenta," Placenta, vol. 26, no. 10, pp. 735-746, 2005.

[3] J. M. Rogers, "Tobacco and pregnancy: overview of exposures and effects," Birth Defects Research Part C, Embryo Today, vol. 84, no. 1, pp. 1-15, 2008.

[4] A. Harlev, A. Agarwal, S. O. Gunes, A. Shetty, and S. S. du Plessis, "Smoking and male infertility: an evidence-based review," The World Journal of Men's Health, vol. 33, no. 3, pp. 143-160, 2015.

[5] L. Storgaard, J. Peter Bonde, E. Ernst et al., "Does smoking during pregnancy affect sons' sperm counts?," Epidemiology, vol. 14, no. 3, pp. 278-286, 2003.

[6] T. K. Jensen, N. Jorgensen, M. Punab et al., "Association of in utero exposure to maternal smoking with reduced semen quality and testis size in adulthood: a cross-sectional study of 1,770 young men from the general population in five European countries," American Journal of Epidemiology, vol. 159, no. 1, pp. 49-58, 2004.

[7] C. H. Ramlau-Hansen, A. M. Thulstrup, L. Storgaard, G. Toft, J. Olsen, and J. P. Bonde, "Is prenatal exposure to tobacco smoking a cause of poor semen quality? A follow-up study," American Journal of Epidemiology, vol. 165, no. 12, pp. 1372-1379, 2007.

[8] C. H. Ramlau-Hansen, A. M. Thulstrup, J. Olsen, E. Ernst, C. Y. Andersen, and J. P. Bonde, "Maternal smoking in pregnancy and reproductive hormones in adult sons," International Journal of Andrology, vol. 31, no. 6, pp. 565-572, 2008.

[9] P. M. Cirillo, B. A. Cohn, N. Y. Krigbaum, M. Lee, C. Brazil, and P. Factor-Litvak, "Effect of maternal coffee, smoking and drinking behavior on adult son's semen quality: prospective evidence from the child health and development studies," Journal of Developmental Origins of Health and Disease, vol. 2, no. 6, pp. 375-386, 2011.

[10] A. Rajpurkar, Y. Jiang, C. B. Dhabuwala, J. C. Dunbar, and $\mathrm{H}$. Li, "Cigarette smoking induces apoptosis in rat testis," Journal of Environmental Pathology, Toxicology and Oncology, vol. 21, pp. 243-248, 2002.

[11] L. B. Hakonsen, A. Ernst, and C. H. Ramlau-Hansen, "Maternal cigarette smoking during pregnancy and reproductive health in children: a review of epidemiological studies," Asian Journal of Andrology, vol. 16, no. 1, pp. 39-49, 2014.

[12] A. Lagunov, M. Anzar, J. C. Sadeu et al., "Effect of in utero and lactational nicotine exposure on the male reproductive tract in peripubertal and adult rats," Reproductive Toxicology, vol. 31, no. 4, pp. 418-423, 2011.

[13] C. C. Paccola, F. M. Neves, I. Cipriano, T. Stumpp, and S. M. Miraglia, "Effects of prenatal and lactation nicotine exposure on rat testicular interstitial tissue," Andrology, vol. 2, no. 2, pp. 175-185, 2014.
[14] A. P. Sobinoff, J. M. Sutherland, E. L. Beckett et al., "Damaging legacy: maternal cigarette smoking has long-term consequences for male offspring fertility," Human Reproduction, vol. 29, no. 12, pp. 2719-2735, 2014.

[15] M. Miranda-Spooner, C. C. Paccola, F. M. Neves, S. U. de Oliva, and S. M. Miraglia, "Late reproductive analysis in rat male offspring exposed to nicotine during pregnancy and lactation," Andrology, vol. 4, no. 2, pp. 218-231, 2016.

[16] C. C. Paccola and S. M. Miraglia, "Prenatal and lactation nicotine exposure affects Sertoli cell and gonadotropin levels in rats," Reproduction, vol. 151, no. 2, pp. 117-133, 2016.

[17] D. S. Huff, D. M. Fenig, D. A. Canning, M. G. Carr, S. A. Zderic, and H. M. Snyder III, "Abnormal germ cell development in cryptorchidism," Hormone Research, vol. 55, no. 1 , pp. 11-17, 2001.

[18] A. L. Drumond, M. L. Meistrich, and H. Chiarini-Garcia, "Spermatogonial morphology and kinetics during testis development in mice: a high-resolution light microscopy approach," Reproduction, vol. 142, no. 1, pp. 145-155, 2011.

[19] G. Manku and M. Culty, "Mammalian gonocyte and spermatogonia differentiation: recent advances and remaining challenges," Reproduction, vol. 149, no. 3, pp. R139-R157, 2015.

[20] P. M. Gocze and D. A. Freeman, "Cytotoxic effects of cigarette smoke alkaloids inhibit the progesterone production and cell growth of cultured MA-10 Leydig tumor cells," European Journal of Obstetrics, Gynecology, and Reproductive Biology, vol. 93, no. 1, pp. 77-83, 2000.

[21] M. Bose, D. Debnath, Y. Chen, and H. S. Bose, "Folding, activity and import of steroidogenic acute regulatory protein into mitochondria changed by nicotine exposure," Journal of Molecular Endocrinology, vol. 39, no. 1, pp. 67-79, 2007.

[22] S. U. Schirmer, I. Eckhardt, H. Lau et al., "The cholinergic system in rat testis is of non-neuronal origin," Reproduction, vol. 142, no. 1, pp. 157-166, 2011.

[23] J. P. Zhang, Q. Y. Meng, Q. Wang, L. J. Zhang, Y. L. Mao, and Z.X. Sun, "Effect of smoking on semen quality of infertile men in Shandong China," Asian Journal of Andrology, vol. 2, no. 2, pp. 143-146, 2000.

[24] K. Husain, B. R. Scott, S. K. Reddy, and S. M. Somani, "Chronic ethanol and nicotine interaction on rat tissue antioxidant defense system," Alcohol, vol. 25, no. 2, pp. 89-97, 2001.

[25] L. C. Murrin, J. R. Ferrer, Z. Wanyun, and N. J. Haley, "Nicotine administration to rats: methodological considerations," Life Sciences, vol. 40, no. 17, pp. 1699-1708, 1987.

[26] W. Lichtensteiger, U. Ribary, M. Schlumpf, B. Odermatt, and H. R. Widmer, "Prenatal adverse effects of nicotine on the developing brain," Progress in Brain Research, vol. 73, pp. 137-157, 1988.

[27] L. Z. Huang, S. H. Hsiao, J. Trzeciakowski, G. D. Frye, and U. H. Winzer-Serhan, "Chronic nicotine induces growth retardation in neonatal rat pups," Life Sciences, vol. 78, no. 13, pp. 1483-1493, 2006.

[28] N. L. Benowitz, J. Hukkanen, and P. Jacob, "Nicotine chemistry, metabolism, kinetics and biomarkers," Handbook of Experimental Pharmacology, vol. 192, pp. 29-60, 2009.

[29] E. J. Mufson, N. Lavine, S. Jaffar, J. H. Kordower, R. Quirion, and H. U. Saragovi, "Reduction in p140-TrkA receptor protein within the nucleus basalis and cortex in Alzheimer's disease," Experimental Neurology, vol. 146, no. 1, pp. 91-103, 1997. 
[30] J. C. Rojas-Castañeda, R. M. Vigueras-Villaseñor, M. ChávezSaldaña et al., "Neonatal exposure to monosodium glutamate induces morphological alterations in suprachiasmatic nucleus of adult rat," International Journal of Experimental Pathology, vol. 97, no. 1, pp. 18-26, 2016.

[31] C. Ríos and A. Santamaría, "Quinolinic acid is a potent lipid peroxidant in rat brain homogenates," Neurochemical Research, vol. 16, no. 10, pp. 1139-1143, 1991.

[32] O. Lowry, N. Rosebrough, A. Farr, and R. Randall, "Protein measurement with the Folin phenol reagent," The Journal of Biological Chemistry, vol. 193, no. 1, pp. 265-275, 1951.

[33] T. L. Ravnborg, T. K. Jensen, A. M. Andersson, J. Toppari, N. E. Skakkebaek, and N. Jorgensen, "Prenatal and adult exposures to smoking are associated with adverse effects on reproductive hormones, semen quality, final height and body mass index," Human Reproduction, vol. 26, no. 5, pp. 1000-1011, 2011.

[34] M. Ernst, E. T. Moolchan, and M. L. Robinson, "Behavioral and neural consequences of prenatal exposure to nicotine," Journal of the American Academy of Child and Adolescent Psychiatry, vol. 40, no. 6, pp. 630-641, 2001.

[35] M. Mochizuki, T. Maruo, K. Masuko, and T. Ohtsu, "Effects of smoking on fetoplacental-maternal system during pregnancy," American Journal of Obstetrics and Gynecology, vol. 149, no. 4, pp. 413-420, 1984.

[36] M. Mochizuki, T. Maruo, and K. Masuko, "Mechanism of foetal growth retardation caused by smoking during pregnancy," Acta Physiologica Hungarica, vol. 65, no. 3, pp. 295-304, 1985.

[37] G. Cohen, J. C. Roux, R. Grailhe, G. Malcolm, J. P. Changeux, and H. Lagercrantz, "Perinatal exposure to nicotine causes deficits associated with a loss of nicotinic receptor function," Proceedings of the National Academy of Sciences, vol. 102, no. 10, pp. 3817-3821, 2005.

[38] A. Hackshaw, C. Rodeck, and S. Boniface, "Maternal smoking in pregnancy and birth defects: a systematic review based on 173687 malformed cases and 11.7 million controls," Human Reproduction Update, vol. 17, no. 5, pp. 589-604, 2011.

[39] C. Chilvers, D. Forman, M. C. Pike, K. Fogelman, and M. E. Wadsworth, "Apparent doubling of frequency of undescended TESTIS in England and Wales in 1962-81," The Lancet, vol. 324, no. 8398, pp. 330-332, 1984.

[40] M. S. Jensen, G. Toft, A. M. Thulstrup, J. P. Bonde, and J. Olsen, "Cryptorchidism according to maternal gestational smoking," Epidemiology, vol. 18, no. 2, pp. 220-225, 2007.

[41] K. Jana, P. K. Samanta, and D. K. De, "Nicotine diminishes testicular gametogenesis, steroidogenesis, and steroidogenic acute regulatory protein expression in adult albino rats: possible influence on pituitary gonadotropins and alteration of testicular antioxidant status," Toxicological Sciences, vol. 116, no. 2, pp. 647-659, 2010.

[42] R. A. Anderson and R. M. Sharpe, "Regulation of inhibin production in the human male and its clinical applications," International Journal of Andrology, vol. 23, no. 3, pp. 136-144, 2000.

[43] L. Marinucci, S. Balloni, C. Bellucci et al., "Effects of nicotine on porcine pre-pupertal sertoli cells: an in vitro study," Toxicology In Vitro, vol. 67, p. 104882, 2020.

[44] M. Culty, "Gonocytes, the forgotten cells of the germ cell lineage," Birth Defects Research. Part C, Embryo Today, vol. 87, no. 1, pp. 1-26, 2009.
[45] Y. Wang and M. Culty, "Identification and distribution of a novel platelet-derived growth factor receptor beta variant: effect of retinoic acid and involvement in cell differentiation," Endocrinology, vol. 148, no. 5, pp. 2233-2250, 2007.

[46] Q. Zhou, Y. Li, R. Nie et al., "Expression of stimulated by retinoic acid gene 8 (Stra8) and maturation of murine gonocytes and spermatogonia induced by retinoic acid in vitro," Biology of Reproduction, vol. 78, no. 3, pp. 537-545, 2008.

[47] L. L. Tres and A. L. Kierszenbaum, "The ADAM-integrintetraspanin complex in fetal and postnatal testicular cords," Birth Defects Research Part C, Embryo Today, vol. 75, no. 2, pp. 130-141, 2005.

[48] M. Y. Tien, S. A. Abeydeera, H. J. Cho et al., "Does the apoptosis pathway play a critical role in gonocyte transformation?," Journal of Pediatric Surgery, vol. 55, no. 9, pp. 1947-1951, 2020.

[49] S.. G. Moréno, B. Dutrillaux, and H. Coffigny, "Status of p53, $\mathrm{p} 21, \mathrm{mdm} 2, \mathrm{pRb}$ proteins, and DNA methylation in gonocytes of control and $\gamma$-irradiated rats during testicular development1," Biology of Reproduction, vol. 64, no. 5, pp. 14221431, 2001.

[50] M. Mosadegh, S. Hasanzadeh, and M. Razi, "Nicotine-induced damages in testicular tissue of rats; evidences for bcl-2, p53 and caspase-3 expression," Iranian Journal of Basic Medical Sciences, vol. 20, no. 2, pp. 199-208, 2017.

[51] R. C. Hogg, M. Raggenbass, and D. Bertrand, "Nicotinic acetylcholine receptors: from structure to brain function," Reviews of Physiology, Biochemistry and Pharmacology, vol. 147, pp. 1-46, 2003.

[52] F. Michelangeli, O. A. Ogunbayo, and L. L. Wootton, "A plethora of interacting organellar Ca2+ stores," Current Opinion in Cell Biology, vol. 17, no. 2, pp. 135-140, 2005.

[53] G. Hajnóczky, G. Csordás, S. Das et al., "Mitochondrial calcium signalling and cell death: approaches for assessing the role of mitochondrial Ca2+ uptake in apoptosis," Cell Calcium, vol. 40, no. 5-6, pp. 553-560, 2006.

[54] J. R. Hom, J. S. Gewandter, L. Michael, S. S. Sheu, and Y. Yoon, "Thapsigargin induces biphasic fragmentation of mitochondria through calcium mediated mitochondrial fission and apoptosis," Journal of Cellular Physiology, vol. 212, no. 2, pp. 498-508, 2007.

[55] M. S. Walters, B. P. de, J. Salit et al., "Smoking accelerates aging of the small airway epithelium," Respiratory Research, vol. 15, no. 1, p. 94, 2014.

[56] A. M. Centner, P. G. Bhide, and G. Salazar, "Nicotine in Senescence and Atherosclerosis," Cells, vol. 9, no. 4, p. 1035, 2020.

[57] Z. L. Wang, L. B. Chen, Z. Qiu et al., "Ginsenoside Rg1 ameliorates testicular senescence changes in D-gal-induced aging mice via anti-inflammatory and antioxidative mechanisms," Molecular Medicine Reports, vol. 17, no. 5, pp. 6269-6276, 2018.

[58] US Environmental Protection Agency (USEPA), Respiratory Health Effects of Passive Smoking, Lung Cancer and Other Disorders, US Environmental Protection Agency (US EPA Publication 600, 6-90/006F), Washington, DC, 1992.

[59] A. Jain and S. J. Flora, "Dose related effects of nicotine on oxidative injury in young, adult and old rats," Journal of Environmental Biology, vol. 33, no. 2, pp. 233-238, 2012.

[60] U. Oztekin, M. Caniklioglu, F. Firat et al., "Carob attenuates nicotine-induced oxidative stress and intratesticular damage in male rats," Andrologia, vol. 52, no. 9, article e13670, 2020. 